\title{
ТЕСТ НА ПОНИМАНИЕ ЭМОЦИЙ: АДАПТАЦИЯ РУССКОЯЗЫЧНОЙ ВЕРСИИ НА РОССИЙСКОЙ ВЫБОРКЕ ДЕТЕЙ ДОШКОЛЬНОГО ВОЗРАСТА
}

\author{
Н.Е. ВЕРАКСА, А.Н. ВЕРАКСА \\ Д.А. БУХАЛЕНКОВА ${ }^{\mathrm{a}}$, К.С. ТАРАСОВА ${ }^{\mathrm{a}}$
}

${ }^{a}$ МГУ имени М.В. Ломоносова, 119991, Россия, Москва, Ленинские горы,, д. 1

\section{Резюме}

В статье представлены результаты адаптации русскоязычной версии методики Тест на понимание эмоций (Test of Emotion Comprehension; Pons, Harris, 2000). Адаптация методики проводилась в период с 2019 по 2020 г. на выборке 596 детей 5-6 лет. Спустя год 351 ребенок был повторно протестирован для оценки способности методики отражать возрастную динамику в развитии понимания эмоций. В целях изучения теоретической структуры, лежащей в основе инструмента, был применен конфирматорный факторный анализ. Эмпирические данные, полученные на российской выборке, подтвердили высокое соответствие русскоязычной версии инструмента ее оригинальной теоретической модели. Результат применения Q-теста Кохрана равенства пропорций указал на приемлемую надежность методики на основе внутренней согласованности ее компонентов. Валидность методики подтверждается наличием умеренных положительных связей общего уровня понимания эмоций и отдельных компонентов теста с распознаванием эмоций по лицевой экспрессии (Affect Recognition subtest NEPSY-II). Как и в оригинальной версии теста, на российской выборке не были выявлены гендерные различия ни по одному из компонентов теста. Анализ связанных с возрастом различий в успешности выполнения методики детьми при первичном и повторном тестировании показал, что количество правильных ответов по всем компонентам методики значимо увеличилось через год после первого обследования, что свидетельствует о способности методики отражать возрастную динамику. В результате работ по адаптации теста были получены российские нормы для детей 5-6 и 6-7 лет. Использование теста в дальнейшем открывает широкие возможности для международного сотрудничества в эмпирических целях для изучения природы понимания эмоций в дошкольном возрасте и в практических для диагностики или разработки программ эмоционального развития детей.

Ключевые слова: понимание эмоций, тест на понимание эмоций, эмоциональное развитие, распознавание эмоций, дошкольный возраст.

\section{Введение}

Понимание эмоций определяется как способность понимать природу, причины и последствия собственных эмоций и эмоций окружающих. Понимание

Исследование выполнено при финансовой поддержке РНФ (проект № 19-18-00521). 
эмоций включает распознавание, описание, объяснение, прогнозирование выражения эмоций в повседневной жизни и контроль над ним (Pons et al., 2004) и является компонентом многоуровневой системы репрезентаций ментальных феноменов и социального познания в подходе «модель психического» (Сергиенко, 2014; Прусакова, 2005). В англоязычной профессиональной литературе устоявшимся термином для обозначения данной линии развития является «theory of mind» (Wellman, 1992; Bender et al., 2011).

Проведенные исследования выявили значимое влияние понимания эмоций на психологическое состояние детей. Было показано, что дети, хорошо понимающие эмоции, реже страдают от тревожных и депрессивных состояний, реже демонстрируют агрессивное поведение (например: Trentacosta, Fine, 2010). Также было показано, что понимание эмоций связано с развитием таких просоциальных компетенций, как взаимодействие и игра со сверстниками (Mathieson, Banerjee, 2011), способность разрешать конфликты (Franco et al., 2017; Liao et al., 2014). В последнее время все большее число исследований показывает, что понимание эмоций является сильным предиктором успешности дальнейшей адаптации детей к школьному обучению (Garrett-Peters et al., 2017) и их академической успеваемости (Franco et al., 2017; Jyzsa, Barrett, 2018). Важно отметить, что результаты проведенных исследований в высокой степени согласуются с теоретическими представлениями, сформулированными А.В. Запорожцем о том, что только согласованное функционирование эмоциональной и когнитивной сфер в их единстве способно обеспечить успешное выполнение ребенком любой деятельности (Запорожец, 1985).

В свете указанных причин оценка понимания эмоций детьми дошкольного возраста представляет интерес как для исследовательской, так и для практической деятельности психологов. В процессе создания, стандартизации и усовершенствования методов в этой области был сформулирован ряд сложностей, с которыми столкнулись разработчики методик по оценке понимания эмоций у детей (Pons, Harris, 2003). Во-первых, отмечается методологическая несогласованность в понимании различных аспектов эмоций. В некоторых случаях не разделяются такие аспекты эмоционального развития, как распознавание эмоций, понимание эмоций, эмоциональная регуляция и теория сознания. Требованием к современным диагностическим инструментам выступает необходимость разделения перечисленных линий эмоционального развития. Другим примером методологической несогласованности является непредставленность в некоторых моделях таких аспектов понимания эмоций, как понимание морально-нравственных конфликтов (стыд, гордость, вина) или смешанных эмоций (радость и страх одновременно). В некоторых моделях также анализируется способность ребенка понимать и отличать друг от друга притворные и реальные эмоции, в то время как в других этот аспект игнорируется. Во-вторых, было выяснено, что диагностика понимания эмоций требует использования невербальных типов заданий, в которых ребенку не нужно использовать речь, чтобы дать ответ. Методики, в которых от ребенка требуется вербальный ответ, могут показать ложный результат из-за потенциального влияния побочных факторов, таких как, например, понимание устной 
речи ребенком или уровень развития коммуникативных навыков. Пример исследования и создания диагностического инструментария при изучении понимания эмоций с учетом указанных требований у российских детей дошкольного возраста представляет диссертационная работа О.А. Прусаковой «Генезис понимания эмоций» (Прусакова, 2005).

За последние несколько десятилетий эмпирические исследования позволили уточнить методологические представления о развитии понимания эмоций. Основным продвижением в этой области является определение и подробное описание основных стадий, через которые проходит развитие понимания эмоций в теоретической модели П. Харриса, Ф. Понса (Pons et al., 2004). Первую стадию дети проходят в возрасте $3-5$ лет, когда учатся понимать внешние причины эмоций (распознавание основных эмоций окружающих по лицевой экспрессии и мимике и понимание влияния внешних обстоятельств и желаний на эмоции). Вторая стадия наступает в возрасте 5-7 лет, в ее ходе дети постепенно понимают, что личные убеждения и воспоминания могут вызывать различные эмоции и что некоторые эмоции можно скрывать. Затем на третьей стадии, в возрасте $7-9$ лет, дети учатся регулировать свои эмоции с помощью когнитивных стратегий, узнают, что моральные правила могут влиять на эмоции и что эмоциональные состояния бывают противоречивыми (Pons, Harris, 2005; Pons et al., 2003; Saltzman et al., 2018).

Для адаптации была выбрана методика Test of Emotion Comprehension (Pons, Harris, 2000), поскольку она наиболее полно соответствует указанным выше методологическим и процедурным критериям. Методика построена на невербальном типе ответов ребенка и позволяет оценить общий уровень понимания эмоций, а также входящие в него компоненты. Соответствие эмпирических данных теоретической структуре инструмента было подтверждено с помощью конфирматорного факторного анализа $\left(\chi^{2}=0.997\right.$; CFI $=1.000$; RMSEA $=0.000)$. С разрешения авторов данная методика была переведена на русский язык (подробное описание методики представлено ниже). Методика переведена на 21 язык и широко используется исследователями в Англии, Италии, Бразилии, Китае, Норвегии и других странах (Albanese et al., 2006; Tang et al., 2018; Fidalgo et al., 2018), что обеспечивает возможность проведения международных исследований. Работы, проведенные с использованием данного теста, показали, что он обладает хорошей надежностью и конструктной валидностью (например: Tang et al., 2018).

Результаты исследований свидетельствуют о наличии индивидуальных различий в способности детей понимать эмоции на каждой стадии. Выявлены некоторые индивидуальные, семейные и культурные факторы, определяющие индивидуальную изменчивость в становлении понимания эмоций: образование матерей (Cutting, Dunn, 1999), убеждения матерей об эмоциях (GarrettPeters et al., 2017; Kerstad, 2016), эмоциональный словарь родителей (Kerstad, 2016). Ряд исследований был посвящен когнитивным и аффективным аспектам развития самого ребенка, которые также влияют на становление способности понимания эмоций (De Stasio et al., 2014; von Salisch et al., 2013). Таким образом, необходимость выработки норм рассматриваемой методики на российской 
выборке продиктована индивидуальной изменчивостью показателей понимания эмоций в дошкольном возрасте, связанной с потенциальным влиянием перечисленных факторов.

\section{Материалы и методы}

\section{Выборка}

Данные для адаптации методики были получены на выборке из 596 детей старшего дошкольного возраста $(\mathrm{M}=5.09, \mathrm{SD}=0.37)$, посещавших муниципальные детские сады г. Москвы. Спустя год 351 ребенок $(\mathrm{M}=6.07, \mathrm{SD}=0.47)$ повторно прошел тестирование для оценки способности методики отражать возрастную динамику в развитии понимания эмоций. Обследование проводилось индивидуально в дошкольных образовательных учреждениях, которые посещали дети. Данные для адаптации методики были собраны в период с 2019 по 2020 г.

\section{Методики}

На основе теоретической модели П. Харриса, Ф. Понса, упомянутой во введении, был разработан Test of Emotion Comprehension (Pons, Harris, 2000). Данный тест предназначен для оценки понимания эмоций у детей в возрасте от 3 до 11 лет. Стимульный материал теста представляет собой иллюстрированную книгу с простыми историями. В каждом задании ребенку рассказывают историю, а затем предлагают выбрать «то чувство, которое испытывает герой истории» из четырех рисунков с различными выражениям лица героя в нижней части страницы. Ответы невербальны, ребенку достаточно указать выбранный вариант. В тесте содержатся контрольные вопросы для проверки понимания ребенком историй. В процессе апробации методики все истории и названия эмоций были переведены на русский язык и затем в процессе обратного перевода отредактированы Франциско Понсом (одним из авторов методики). Также с авторами методики были обсуждены и согласованы процедурные особенности проведения теста.

Методика имеет трехуровневую структуру понимания эмоций, которая включает Внешний, Психический компоненты и Мета компонент. Каждый компонент содержит в себе несколько показателей, описание которых приведено ниже (см. рисунок 1). Первый компонент, который обозначен авторами как «Внешний», является базовым и сосредоточен на внешних аспектах эмоций. Второй компонент, названный авторами «Психический», является промежуточным по уровню сложности и включает в себя различные психические аспекты понимания эмоций. Третий компонент «Мета» является самым сложным и сосредоточен на понимании детьми того, как человек может отслеживать и анализировать собственные эмоциональные состояния. По каждому компоненту баллы варьируются от 0 до 3. Общий уровень понимания эмоций определяется путем вычисления суммы баллов по всем компонентам и составляет от 0 до 9 баллов. 


\section{Структура методики Тест на понимание эмоций}

Рисунок 1

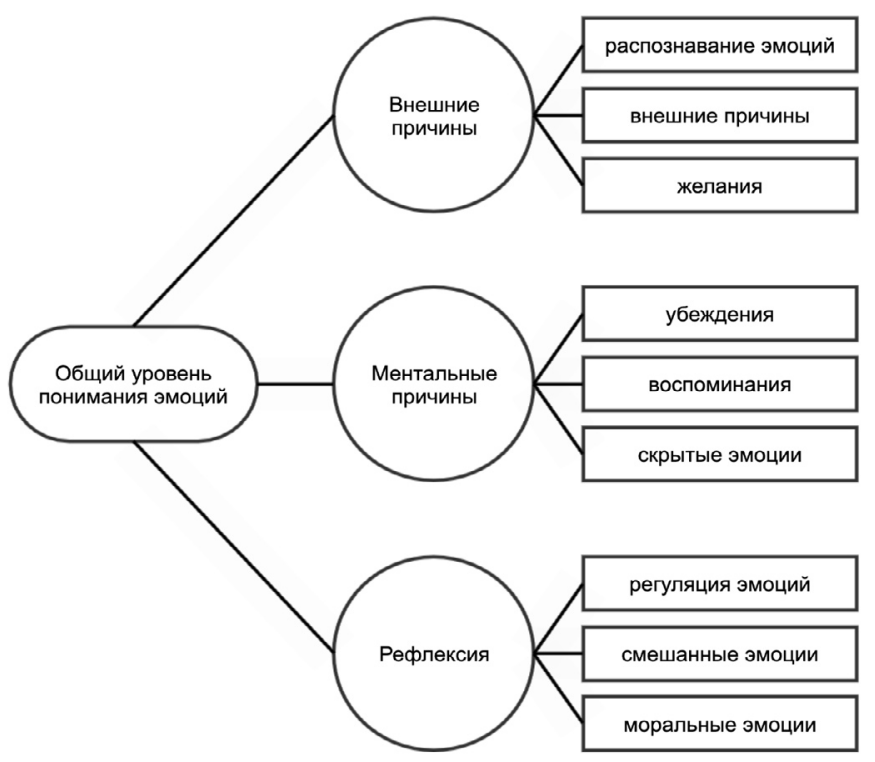

(I) Распознавание эмоций - показатель, который оценивает способность ребенка распознавать и называть эмоции. В тесте содержится пять заданий на оценку данного показателя. Все задания построены следующим образом: «Посмотри на эти четыре картинки и покажи мальчика (или девочку), которому грустно».

(II) Внешние причины - показатель, который оценивает понимание ребенком того, что эмоции могут быть вызваны внешними ситуациями. В тесте содержится четыре задания, направленные на оценку данного показателя. Пример задания: «Катя получает подарок на день рождения. Что чувствует Катя в этот момент?»

(III) Желания - показатель, который оценивает понимание того, что два человека могут испытывать разные эмоции по поводу одной и той же ситуации из-за того, что у них разные желания. В тесте содержится два задания на оценку данного показателя. Пример задания: «Саша любит кока-колу, а Сережа ненавидит кока-колу. Когда они захотели пить, то обнаружили, что в холодильнике есть бутылка кока-колы. Что чувствует Саша? А что чувствует Сережа?»

(IV) Убеждения - показатель, который оценивает понимание того, что убеждения людей могут влиять на то, какие эмоции вызывает у них та или иная ситуация. Тест содержит одно задание, которое направлено на оценку данного показателя: «Это кролик, а это волк, который хочет его съесть». Ребенку показывают изображение волка, а затем закрывают заслонкой, показывая, что он прячется за деревьями. «Знает ли кролик, что волк прячется за кустами? Что сейчас чувствует кролик?» 
(V) Воспоминания - показатель, который оценивает понимание того, что воспоминания могут оказывать влияние на эмоциональные переживания. В тесте содержится одно задание, которое направлено на оценку данного показателя: «Алиса очень грустит, потому что ее кролика съел волк. На следующий день Алиса смотрит на фотографию своей подруги. Что в этот момент чувствует Алиса? А потом Алиса увидела на фото своего кролика. Что в этот момент чувствует Алиса?»

(VI) Cкрытыле эмоции - показатель, который оценивает понимание несоответствия между реальными и внешне выражаемыми эмоциями. В тесте содержится одно задание, которое направлено на оценку данного показателя: «У Вани есть магнитные шарики, а у Коли такой игрушки нет. Коля улыбается, потому что не хочет показывать Ване, что он чувствует внутри. Что Коля чувствует на самом деле?»

(VII) Регуляция эмоций - показатель, который оценивает понимание того, что с негативными эмоциями можно совладать с помощью когнитивных стратегий. В тесте содержится одно задание, которое направлено на оценку данного показателя: «Алиса грустит из-за того, что ее кролика больше нет. Что она может сделать, чтобы справиться с грустью?»

(VIII) Смешанные әмоции - показатель, который оценивает понимание того, что люди могут иметь противоречивые смешанные эмоции в связи с определенными ситуациями. В тесте содержится одно задание, которое направлено на оценку данного показателя: «Маша смотрит на свой новый велосипед, который ей только что подарили. Но думает, что может поранить себя, потому что раньше никогда не ездила на двухколесном велосипеде. Что сейчас чувствует Маша?»

(IX) Моральные эмоции - показатель, который оценивает осознание того, что негативные эмоции возникают в результате морально неприемлемого поведения и, наоборот, позитивные эмоции - от морально одобряемых поступков. В тесте содержится одно задание, которое направлено на оценку данного показателя: «Вова был в гостях и взял шоколадное печенье без разрешения матери своего друга, и он решил никогда не признаваться в этом проступке. Что Вова чувствует по этому поводу?»

Для проверки конструктной валидности теста была применена русскоязычная версия субтеста Affect Recognition из батареи психоневрологических тестов NEPSY-II (Developmental NEuroPSYchological Assessment) (Korkman et al., 2007). Данная методика направлена на оценку способности распознавать эмоции по лицевой экспрессии. Диагностику проводили опытные тестеры, прошедшие обучение по применению инструментария NEPSY-II на английском языке. Испытуемым демонстрировались фотографии детских лиц, которые выражают радость, грусть, гнев, страх, отвращение и спокойствие, и просили в каждом задании показать двух детей, которые испытывают одно и то же чувство. Методика широко применяется в зарубежной исследовательской практике. Однако поскольку она не адаптирована на российской выборке, в данном исследовании была проведена оценка ее одномерности с помощью конфирматорного факторного анализа. Полученные значения свидетельствуют о 
соответствии эмпирических данных ожидаемой модели «один фактор на шкалу»: $\chi^{2} / \mathrm{df}=182.893 / 119(p<0.001)$; сравнительный индекс пригодности $\mathrm{CFI}=0.823$; среднеквадратичная ошибка приближения RMSEA =0.037. Ранее в ряде эмпирических исследований (например: Korkman et al., 2007; Kervinen, 2015) было подтверждено, что способности, оцениваемые с помощью данной методики, образуют единый фактор эмоционального развития, куда относится также и понимание эмоций. Теоретически ожидаемо наличие значимой связи между результатами детей по данному тесту и Внешним компонентом Теста на понимание эмоций, поскольку и в том и в другом случае речь идет о распознавании эмоций по лицевой экспрессии. Внешний компонент методики Тест на понимание эмоций дополнительно включает в себя и понимание внешних причин эмоций, и понимание влияния желаний на эмоции.

\section{Результаты адаптации теста}

\section{Оценка структуры методики}

Факторная структура русскоязычной версии методики Тест на понимание эмоций прошла оценку с помощью конфирматорного факторного анализа. Анализ проводился с использованием программы Structural Equation Modeling Software v.6.2 (EQS v.6.2). В качестве метода оценки модели были использованы индексы: значение критерия $\chi^{2} / \mathrm{df}=22.702 / 24(p=0.53)$; сравнительный индекс пригодности CFI = $1.000>0.90$; среднеквадратичная ошибка приближения RMSEA $=0.000<0$. Полученные значения свидетельствуют о высоком соответствии русскоязычной версии инструмента ее оригинальной теоретической модели. Эмпирические данные, полученные на российской выборке, соответствуют исходной модели с тремя факторами (Внешний, Психический, Мета). Корректировка модели не потребовалась.

\section{Оценка надежности теста}

Для оценки надежности был применен Q-тест Кохрана равенства пропорций, поскольку все пункты адаптируемого инструмента являются дихотомическими. На материале полученных эмпирических данных Q-тест Кохрана позволил оценить, одинаково ли оказался расщеплен набор дихотомических пунктов по Внешнему, Психическому и Мета компонентам теста, каждый из которых содержит по три дихотомических показателя. Статистическая значимость коэффициентов равенства пропорций по каждому из компонентов оказалась меньше критического значения $(p \leqslant 0.005)$, что свидетельствует о внутренней согласованности компонентов адаптируемого инструмента.

\section{Проверка нормальности распределения}

Проверка нормальности распределения с помощью теста КолмогороваСмирнова была проведена для трех основных компонентов теста (Внешний, 
Психический, Мета) и для общего уровня понимания эмоций (общий балл). Тест Колмогорова-Смирнова показал, что распределение данных не соответствует нормальному по всем показателям. При этом наблюдается эффект потолка по Внешнему компоненту теста, что соответствует установленной возрастной периодизации развития понимания эмоций, согласно которой указанный компонент понимания эмоций окончательно формируется в возрасте 3-5 лет (рисунок 2).

\section{Оценка конструктной валидности теста}

Анализ конструктной валидности производился путем корреляционного анализа связи компонентов адаптируемого инструмента с результатами русскоязычной версии широко используемой в зарубежной исследовательской практике методики, направленной на оценку распознавания эмоции (Affect Recognition). Так как распределение данных по используемым методикам не соответствовало нормальному, был применен критерий корреляции Спирмена. Результаты представлены в таблице 1.

Рисунок 2

Распределение баллов по трем компонентам методики и общему уровню понимания эмоций $(\mathrm{N}=596)$
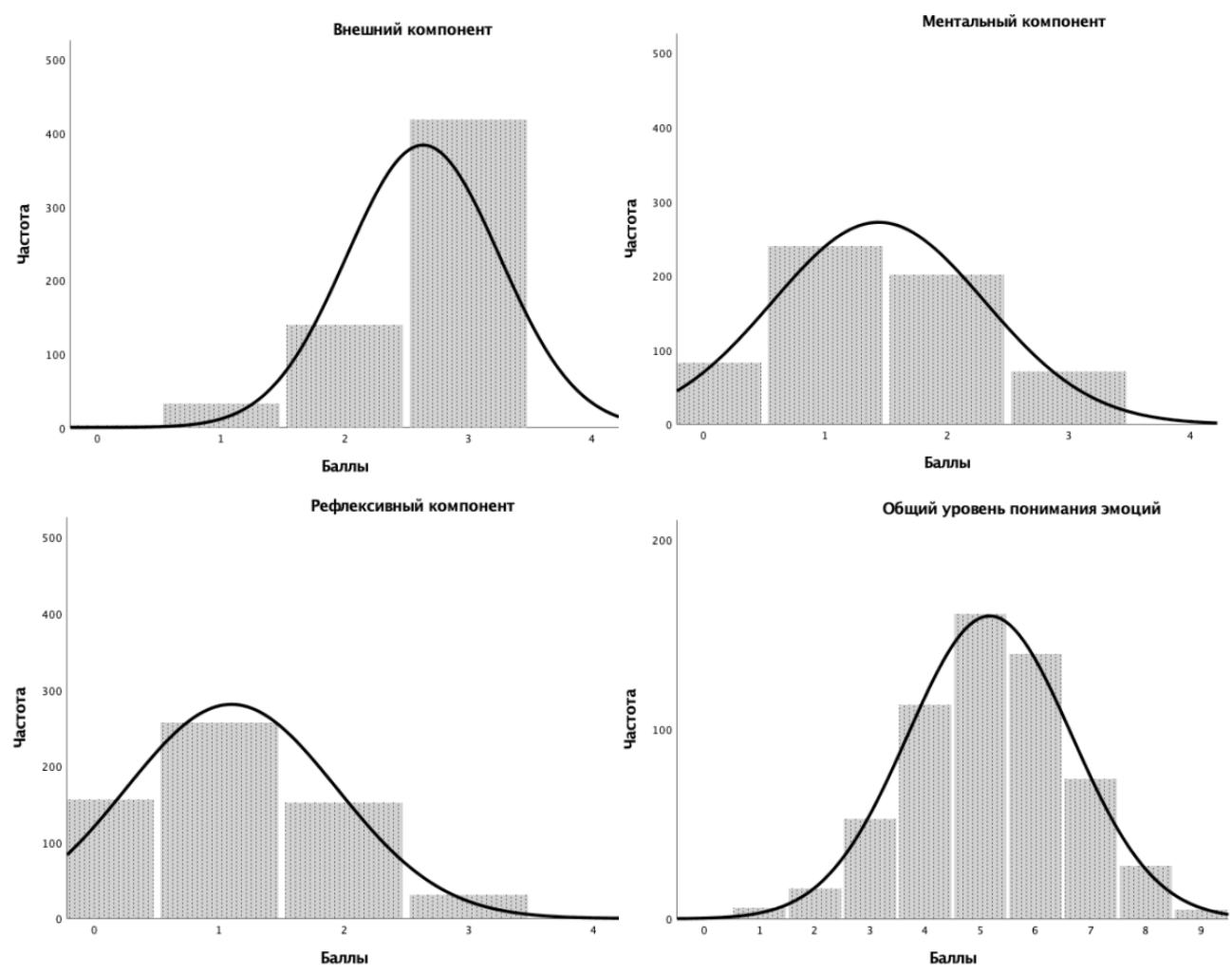
Связь компонентов Теста на понимание эмоций с распознаванием эмоций $(\mathrm{N}=596)$

\begin{tabular}{|l|c|c|c|c|}
\hline & $\begin{array}{c}\text { Внешний } \\
\text { компонент }\end{array}$ & $\begin{array}{c}\text { Психический } \\
\text { компонент }\end{array}$ & Мета компонент & Общий балл \\
\hline Внешний компонент & - & & & \\
\hline Психический компонент & $0.102^{*}$ & - & & \\
\hline Мета компонент & 0.038 & $0.130^{* *}$ & - & \\
\hline Общий балл & $0.453^{* *}$ & $0.712^{* *}$ & $0.651^{* *}$ & - \\
\hline Распознавание эмоций & $0.185^{* *}$ & $0.082^{*}$ & $0.085^{*}$ & $0.165^{* *}$ \\
\hline
\end{tabular}

${ }^{*} p<0.05,{ }^{* *} p<0.01$.

Выявлена теоретически ожидаемая значимая положительная связь между общим баллом адаптируемого инструмента и способностью детей распознавать эмоции. Отдельно Внешний компонент оказался умеренно связан со способностью распознавать эмоции, абсолютные значения полученного коэффициента при этом соответствуют ожидаемым. Психический компонент слабо связан с распознаванием эмоций, что, вероятно, обусловлено сфокусированностью данного компонента теста на ментальных причинах эмоций, что не всегда связано с лицевой экспрессией. Связь Мета компонента со способностью распознавать эмоции также оказалась слабой, что может быть частично объяснено тем, что отслеживание и анализ собственных эмоциональных состояний могут зачастую не выражаться с помощью лицевой экспрессии.

\section{Нормы и гендерные различия}

Анализ гендерных различий был произведен с применением непараметрического критерия Манна-Уитни, так как распределение баллов по всем показателям теста отличалось от нормального. Различия между успешностью выполнения теста девочками и мальчиками не были выявлены как по общему уровню понимания эмоций, так и по отдельным компонентам (таблица 2). Линейный регрессионный анализ также показал, что пол ребенка не является значимым предиктором общего уровня понимания эмоций $(\beta=0.177 ; p=0.147)$.

Спустя год после первого тестирования часть детей прошла повторное тестирование, что позволило получить данные о развитии понимания эмоций

Нормы выполнения теста для детей 5-6 лет $(\mathrm{N}=596)$

\begin{tabular}{|l|c|c|c|c|}
\hline \multirow{2}{*}{} & \multicolumn{2}{|c|}{ Мальчики (N = 299) } & \multicolumn{2}{c|}{ Девочки (N = 297) } \\
\cline { 2 - 5 } & $\mathrm{M}$ & $\mathrm{SD}$ & $\mathrm{M}$ & $\mathrm{SD}$ \\
\hline Внешний компонент & 2.63 & 0.62 & 2.64 & 0.62 \\
\hline Психический компонент & 1.37 & 0.86 & 1.51 & 0.88 \\
\hline Мета компонент & 1.08 & 0.81 & 1.11 & 0.88 \\
\hline Общий балл & 5.08 & 1.43 & 5.26 & 1.54 \\
\hline
\end{tabular}


с течением времени. Результаты повторного тестирования приведены в таблице 3 отдельно для девочек и мальчиков. Анализ гендерных различий с применением непараметрического критерия Манна-Уитни при повторном тестировании также не выявил значимых различий между девочками и мальчиками ни по одному из компонентов методики.

Т-критерий Вилкоксона был применен для анализа связанных с возрастом различий в успешности выполнения методики детьми при первичном и повторном тестировании. Анализ показал, что количество правильных ответов по всем компонентам методики значимо увеличилось через год после первого обследования (общий уровень понимания эмоций $Z=-9.56$, при $p<0.001$; Внешний компонент $Z=-7.27$, при $p<0.001$; Психический компонент $Z=-7.13$, при $p<0.001$; Мета компонент $Z=-5.73$, при $p<0.001)$. Результаты анализа свидетельствуют о том, что адаптируемый инструмент отражает возрастную динамку в развитии как общего уровня понимания эмоций, так и его компонентов.

\section{Обсуждение и заключение}

Применение методики Тест на понимание эмоций позволяет оценивать девять показателей понимания эмоций у детей дошкольного возраста. Результаты применения методики позволяют увидеть подробную картину развития понимания эмоций у детей с 3 до 11 лет. Несмотря на то что для полного завершения адаптации методики необходимы значительные усилия, настоящая работа позволяет уточнить представления об особенностях развития понимания эмоций у российских детей 5-7 лет.

Одно из существенных преимуществ данной методики заключается в том, что, несмотря на относительную простоту процедуры проведения, получаемые данные позволяют проанализировать развитие сразу нескольких компонентов и ряда отдельных показателей понимания эмоций (Rocha et al., 2015). Проверка соответствия факторной структуры русскоязычной версии методики с помощью конфирматорного факторого анализа подтвердила, что полученные на российской выборке детей 5-6 лет эмпирические данные укладываются в заданную при разработке теоретическую трехкомпонентную модель (Внешний, Психический и Мета).

Оценка конструктной валидности была произведена с помощью корреляционного анализа компонентов методики с результатами выполнения детьми

Таблица 3

Нормы выполнения теста для детей 6-7 лет $(\mathrm{N}=351)$

\begin{tabular}{|l|c|c|c|c|}
\hline \multirow{2}{*}{} & \multicolumn{2}{|c|}{ Мальчики (N = 171) } & \multicolumn{2}{c|}{ Девочки (N = 180) } \\
\cline { 2 - 5 } & $\mathrm{M}$ & $\mathrm{SD}$ & $\mathrm{M}$ & $\mathrm{SD}$ \\
\hline Внешний компонент & 2.88 & 0.38 & 2.82 & 0.45 \\
\hline Психический компонент & 1.71 & 0.88 & 1.72 & 0.82 \\
\hline Мета компонент & 1.43 & 0.83 & 1.52 & 0.94 \\
\hline Общий балл & 6.02 & 1.29 & 6.06 & 1.40 \\
\hline
\end{tabular}


теста на распознавание эмоций. Общий уровень понимания эмоций и Внешний компонент теста оказались значимо умеренно связаны с распознаванием эмоций по лицевой экспрессии, что соответствовало теоретическим ожиданиям. Однако связь Психического и Мета компонентов адаптируемого инструмента с распознаванием эмоций оказалась слабой, что, вероятно, объясняется ментальной нагрузкой указанных компонентов. Наличие в методике заданий различного уровня сложности позволяет использовать ее для диагностики детей в достаточно широком возрастном диапазоне. В рамках данного исследования был проведен анализ связанных с возрастом различий в успешности выполнения методики детьми. Количество правильных ответов по всем компонентам методики значимо увеличилось через год после первого обследования, что свидетельствует о том, что адаптируемый инструмент способен отражать возрастную динамку. Как и в оригинальной версии теста, в русскоязычной выборке не были выявлены гендерные различия ни по одному из компонентов теста. Аналогичные результаты были получены при адаптации данного теста на итальянской, английской и китайской выборке (Albanese et al., 2006; Tang et al., 2018; Fidalgo et al., 2018).

В целом результаты проведенного психометрического анализа подтверждают пригодность адаптированной русскоязычной версии Теста на понимание эмоций. Данная методика представляет собой надежный, валидный инструмент оценки понимания эмоций, в том числе и при применении на российской выборке. В результате работ по адаптации теста были получены российские нормы для детей в возрасте 5-6 и 6-7 лет. Возможно использование теста в эмпирических целях для изучения природы понимания эмоций в дошкольном и начальном школьном возрасте, а также в практических целях для диагностики с последующей дачей индивидуальных рекомендаций или разработкой программ эмоционального развития детей дошкольного и младшего школьного возраста. Применение русскоязычной версии теста открывает большие возможности для международного сотрудничества, поскольку ранее инструмент уже был переведен на 21 язык, адаптирован и широко используется исследователями в Англии, Италии, Бразилии, Китае, Норвегии и других странах.

\section{Литература}

Запорожец, А. В. (1985). Воспитание эмоций и чувств у дошкольника. В кн. А. Д. Кошелева (ред.), Эмоииональное развитие дошкольника (с. 26-28). М.: Просвещение.

Прусакова, О. А. (2005). Генезис понимания эмоций (Докторская диссертация). Государственный университет гуманитарных наук, Москва.

Сергиенко, Е. А. (2014). Модель психического как парадигма познания социального мира. Психологические исследования: электронный научный журнал, 7(36), 6. Режим доступа: http://psystudy.ru

Ссылки на зарубежные источники см. в разделе References после англоязычного блока. 
Веракса Николай Евгеньевич - профессор, кафедра психологии образования и педагогики, факультет психологии, МГУ имени М.В. Ломоносова, доктор психологических наук, профессор.

Сфера научных интересов: дошкольное образование, педагогика, психология развития.

Контакты: neveraksa@gmail.com

Веракса Александр Николаевич - заведующий кафедрой, кафедра психологии образования и педагогики, факультет психологии, МГУ имени М.В. Ломоносова, доктор психологических наук, профессор.

Сфера научных интересов: психология образования, педагогика, эмоциональное развитие. Контакты: veraksa@yandex.ru

Гаврилова Маргарита Николаевна - младший научный сотрудник, кафедра психологии образования и педагогики, факультет психологии, МГУ имени М.В. Ломоносова.

Сфера научных интересов: психология эмоций, дошкольный возраст.

Контакты: gavrilovamrg@gmail.com

Бухаленкова Дарья Алексеевна - младший научный сотрудник, кафедра психологии образования и педагогики, факультет психологии, МГУ имени М.В. Ломоносова.

Сфера научных интересов: психология эмоций, регуляторные функции, психология образования.

Контакты: d.bukhalenkova@inbox.ru

Тарасова Кристина Сергеевна - младший научный сотрудник, кафедра психологии образования и педагогики, факультет психологии, МГУ имени М.В. Ломоносова.

Сфера научных интересов: психология эмоций, регуляторные функции, психология образования.

Контакты: christinap@bk.ru

\title{
The Russian Version of the Test of Emotion Comprehension: Adaptation and Validation for Use in Preschool Children
}

\author{
N.E. Veraksa ${ }^{a}$, A.N. Veraksa ${ }^{a}$, M.N. Gavrilova ${ }^{a}$, D.A. Bukhalenkova ${ }^{a}$, K.S. Tarasova ${ }^{a}$ \\ ${ }^{a}$ Lomonosov Moscow State University, 1 Leninskie Gory, Moscow, 119991, Russian Federation
}

\begin{abstract}
The article presents the results of the Russian adaptation of the Test of Emotion Comprehension (Pons, Harris, 2000). The adaptation was conducted between 2019 and 2020 on a sample of 596 children 5-6 years old. One year later, 351 children were retested to assess the ability of the tool to reflect age dynamics in development of emotion understanding. Confirmatory factor analysis was applied to examine the theoretical structure underlying the tool. The empirical data obtained on the Russian sample confirmed the high correspondence of the Russian version of the tool to its original theoretical model. The result of applying Cochran's Q-test of equal proportions indicated acceptable reliability of the tool based on the internal consistency of its components. The validity of the test is confirmed by moderate positive correlations between the general level of emotion comprehension and individual test components with facial
\end{abstract}


emotion recognition (Affect Recognition subtest NEPSY-II). Similar to the original version of the test, no gender differences were revealed for any of the test components in the Russian sample. The analysis of age-related differences in children's performance on the test during initial and repeated testing showed that the number of correct answers in all components of the test significantly increased one year after the first examination, which verifies the ability of the instrument to reflect age dynamics. As a result of adaptation of the test, Russian norms for children of 5-6 and 6-7 years old were obtained. The future application of the test opens up broad possibilities for international cooperation in empirical studies of the nature of emotion understanding in preschool age and in practical tasks, such as diagnostics or design of programs for children's emotional development.

Keywords: emotion understanding, Test of Emotion Comprehension, emotional development, emotion recognition, preschool age.

\section{References}

Albanese, O., Grazzani, I., Molina, P., Antoniotti, C., Arati, L., Farina, E., \& Pons, F. (2006). Children's emotion understanding: preliminary data from the Italian validation project of Test of Emotion Comprehension (TEC). In F. Pons et al. (Eds.), Toward emotional competences (pp. 39-53). Aalborg, DK: Aalborg University Press.

Bender, P. K., Pons, F., Harris, P. L., \& de Rosnay, M. (2011). Do young children misunderstand their own emotions? European Journal of Developmental Psychology, 8(3), 331-348.

Cutting, A. L., \& Dunn, J. (1999). Theory of mind, emotion understanding, language, and family background: Individual differences and interrelations. Child Development, 70(4), 853-865. doi:10.1111/1467-8624.00061

De Stasio, S., Fiorilli, C., \& Di Chiacchio, C. (2014). Effects of verbal ability and fluid intelligence on children's emotion understanding. International Journal of Psychology, 49(5), 409-414. doi:10.1002/ijop.12032

Fidalgo, A. M., Tenenbaum, H. R., \& Aznar, A. (2018). Are there gender differences in emotion comprehension? Analysis of the test of emotion comprehension. Journal of Child and Family Studies, 27(4), 1065-1074.

Franco, M. da G., Beja, M. J., Candeias, A., \& Santos, N. (2017). Emotion understanding, social competence and school achievement in children from primary school in Portugal. Frontiers in Psychology, 8, 1-15. doi:10.3389/fpsyg.2017.01376

Garrett-Peters, P. T., Castro, V. L., \& Halberstadt, A. G. (2017). Parents' beliefs about children's emotions, children's emotion understanding, and classroom adjustment in middle childhood. Social Development, 26(3), 575-590. doi:10.1111/sode.12222

Jyzsa, K., \& Barrett, K. C. (2018). Affective and social mastery motivation in preschool as predictors of early school success: a longitudinal study. Early Childhood Research Quarterly, 45, 81-92. doi:10.1016/j.ecresq.2018.05.007

Kerstad, S. B. (2016). Young children's emotion understanding: The impact of parent and child factors, socioeconomic status, and culture (Thesis for the Degree of Philosophiae Doctor). Norwegian University of Science and Technology, Trondheim. Retrieved from https://ntnuopen.ntnu.no/ntnu- 
xmlui/bitstream/handle/11250/2409891/Silja\%20Berg\%20K\%c3\%a5rstad_PhD.pdf?sequence=1 \&isAllowed $=\mathrm{y}$

Kervinen, S. (2015). Exploration of the internal structure of the NEPSY-II (Master's Thesis). University of Helsinki, Finland. Retrieved from https://helda.helsinki.fi/bitstream/handle/10138/156462/ Silja_Kervinen_pg_2015.pdf

Korkman, M., Kirk, U., \& Kemp, S. (2007). Administration manual NEPSY-II. San Antonio, TX: Harcourt Assessment.

Liao, Z., Li, Y., \& Su, Y. (2014). Emotion understanding and reconciliation in overt and relational conflict scenarios among preschoolers. International Journal of Behavioral Development, 38(2), 111117. doi:10.1177/0165025413512064

Mathieson, K., \& Banerjee, R. (2011). Peer play, emotion understanding, and socio-moral explanation: The role of gender. British Journal of Developmental Psychology, 29(2), 188-196. doi:10.1111/j.2044-835X.2010.02020.x

Pons, F., \& Harris, P. (2000). Test of emotion comprehension: TEC. University of Oxford.

Pons, F., \& Harris, P. L. (2005). Longitudinal change and longitudinal stability of individual differences in children's emotion understanding. Cognition and Emotion, 19(8), 1158-1174. doi:10.1080/02699930500282108

Pons, F., Harris, P. L., \& de Rosnay, M. (2004). Emotion comprehension between 3 and 11 years: Developmental periods and hierarchical organization. European Journal of Developmental Psychology, 1(2), 127-152. doi:10.1080/17405620344000022

Pons, F., Lawson, J., Harris, P. L., \& De Rosnay, M. (2003). Individual differences in children's emotion understanding. Scandinavian Journal of Psychology, 44(4), 347-353. doi:10.1111/14679450.00354

Prusakova, O. A. (2005). Genezis ponimaniya emotsii [The genesis of understanding emotions] (Doctoral dissertation). Gosudarstvennyi Universitet Gumanitarnykh Nauk, Moscow, Russian Federation. (in Russian)

Rocha, A., Roazzi, A., Da Silva, A., Candeias, A., Minervino, C. M., Roazzi, M., \& Pons, F. (2015). Test of emotion comprehension: Exploring the underlying structure through Confirmatory Factor Analysis and Similarity Structure Analysis. In A. Roazzi, B. Campello, \& W. Bilsky (Eds.), Facet theory: Searching for structure in complex social, cultural and psychological phenomena (pp. 66-84). Recife, BR: Editora UFPE.

Saltzman, J. A., Fiese, B. H., Bost, K. K., \& McBride, B. A. (2018). Development of appetite self-regulation: Integrating perspectives from attachment and family systems theory. Child Development Perspectives, 12(1), 51-57. doi:10.1111/cdep.12254

Sergienko, E. A. (2014). Theory of Mind as a paradigm of social cognition. Psikhologicheskie Issledovaniya, 7(36), 6. Retrieved from http://psystudy.ru (in Russian)

Tang, Y., Harris, P. L., Pons, F., Zou, H., Zhang, W., \& Xu, Q. (2018). The understanding of emotion among young Chinese children. International Journal of Behavioral Development, 42(5), 512-517.

Trentacosta, C. J., \& Fine, S. E. (2010). Emotion knowledge, social competence, and behavior problems in childhood and adolescence: a meta-analytic review. Social Developement, 19(1), 1-29. doi:10.1111/j.1467-9507.2009.00543.x

Von Salisch, M., Haenel, M., \& Freund, P. A. (2013). Emotion understanding and cognitive abilities in young children. Learning and Individual Differences, 26, 15-19. doi:10.1016/j.lindif.2013.04.001

Wellman, H. M. (1992). The child's theory of mind. The MIT Press. 
Zaporozhets, A. V. (1985). Vospitanie emotsii i chuvstv u doshkol'nika [Cultivation of emotions and feelings in a preschooler]. In A. D. Kosheleva (Ed.), Emotsional'noe razvitie doshkol'nika [Emotional development of a preschooler] (pp. 26-28). Moscow: Prosveshchenie. (in Russian)

Nikolay E. Veraksa - Professor, chair of psychology of education and pedagogy, Faculty of Psychology, Lomonosov Moscow State University.DSc in Psychology, Professor.

Research Area: preschool education, pedagogy, psychology of development.

E-mail: neveraksa@gmail.com

Alexander N. Veraksa - Head, chair of psychology of education and pedagogy, Faculty of Psychology, Lomonosov Moscow State University, DSc in Psychology, Professor.

Research Area: psychology of education, pedagogy, emotional development.

E-mail: veraksa@yandex.ru

Margarita N. Gavrilova - Junior Research Fellow, chair of psychology of education and pedagogy, Faculty of Psychology, Lomonosov Moscow State University.

Research Area: psychology of emotions, preschool age.

E-mail: gavrilovamrg@gmail.com

Daria A. Bukhalenkova - Junior Research Fellow, chair of psychology of education and pedagogy, Faculty of Psychology, Lomonosov Moscow State University.

Research Area: psychology of emotions, regulatory functions, psychology of education.

E-mail: d.bukhalenkova@inbox.ru

Kristina S. Tarasova - Junior Research Fellow, chair of psychology of education and pedagogy, Faculty of Psychology, Lomonosov Moscow State University.

Research Area: psychology of emotions, regulatory functions, psychology of education.

E-mail: christinap@bk.ru 